\title{
Les conséquences d'une libéralisation du secteur agricole pour les pays en développement et la Suisse
}

Auswirkungen einer Liberalisierung im Agrarsektor auf Entwicklungsländer und die Schweiz

Heidi Bravo-Baumann

\section{OpenEdition} Journals

Édition électronique

URL : http://journals.openedition.org/aspd/1426

DOI : $10.4000 /$ aspd. 1426

ISSN : 1663-9669

\section{Éditeur}

Institut de hautes études internationales et du développement

\section{Édition imprimée}

Date de publication : 1 février 1993

Pagination : 173-191

ISSN : 1660-5934

Référence électronique

Heidi Bravo-Baumann, "Les conséquences d'une libéralisation du secteur agricole pour les pays en développement et la Suisse », Annuaire suisse de politique de développement [En ligne], 12 | 1993, mis en ligne le 30 avril 2013, consulté le 08 septembre 2020. URL : http://journals.openedition.org/aspd/1426 ; DOI : https://doi.org/10.4000/aspd.1426

Ce document a été généré automatiquement le 8 septembre 2020

(c) The Graduate Institute I Geneva 


\section{Les conséquences d'une} libéralisation du secteur agricole pour les pays en développement et la Suisse

Auswirkungen einer Liberalisierung im Agrarsektor auf Entwicklungsländer und die Schweiz

Heidi Bravo-Baumann

\section{NOTE DE L'ÉDITEUR}

En français, résumé seulement. Lire l'article original en allemand dans Schweizerisches Jahrbuch für Entwicklungspolitik : « Auswirkungen einer Liberalisierung im Agrarsektor auf Entwicklungsländer und die Schweiz », http://sjep.revues.org/1242.

\section{RÉSUMÉS}

Cet article présente l'évolution du commerce international de produits agricoles au cours des trente dernières années ainsi que les intérêts en jeu dans ce domaine. La libéralisation de ce commerce est un enjeu central de l'Uruguay Round. En ce qui concerne la Suisse, une telle libéralisation assouplirait le système fondé sur le protectionnisme et les contingents de production ; les prix au producteur baisseraient et le marché exercerait un peu mieux sa fonction régulatrice. Les pertes de revenus des paysans devraient être en partie compensées par des 
paiements directs de façon à ce que l'agriculture suisse puisse continuer à assumer son rôle dans l'économie et la société.

Les effets d'une libéralisation pour les pays en développement dépendent de la situation de chaque pays, de son agriculture et de sa politique économique. Ces effets dépendent en outre de l'ampleur de la libéralisation et des pays qui poursuivent cette politique. D'une manière générale, on peut attendre d'une libéralisation qu'elle modifie les prix relatifs des matières premières agricoles et des produits alimentaires en faveur de ces derniers. Dans des conditions favorables, la production d'aliments, le degré d'autosuffisance et la sécurité alimentaire augmenteraient. La possibilité pour les pays en développement d'accroitre leurs exportations de produits agricoles dépendra beaucoup de l'évolution de l'agriculture des pays d'Europe de l'Est. Une libéralisation du commerce agricole de la Suisse pourrait avoir un impact positif pour les pays en développement, bien que très limité en raison de la faible dimension du marché helvétique.

\section{AUTEUR}

\section{HEIDI BRAVO-BAUMANN}

Dr. Agrarökonomin, Institut fur Agrarwirtscnaft, ETH-Zentrum 